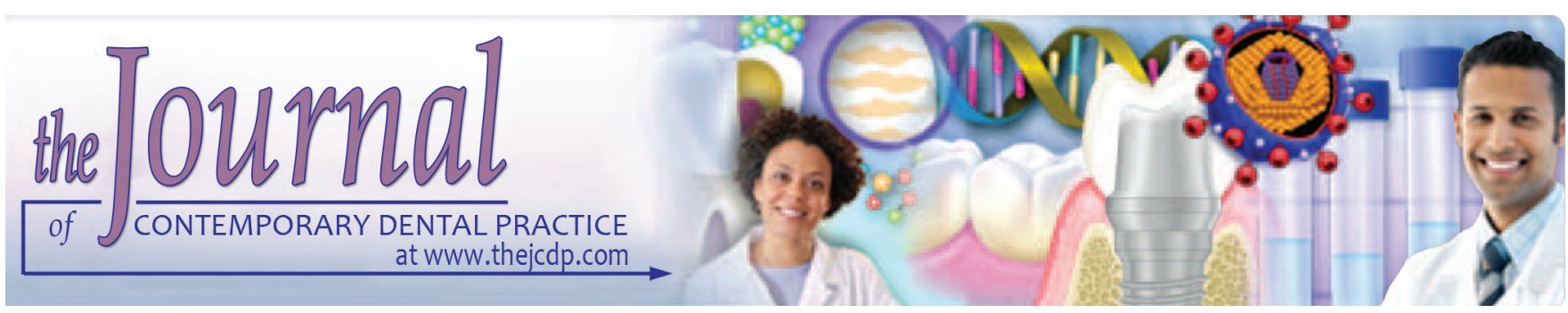

\title{
Effect of Different Dentifrices on the Surface Roughness of Acrylic Resins: An in vitro Study
}

\author{
${ }^{1}$ Nitin Gautam, ${ }^{2}$ Aditi Sharma, ${ }^{3}$ Unjum Bashir, ${ }^{4}$ Sisir Rapolu, ${ }^{5}$ Nallamilli Mamatha, ${ }^{6}$ Siripurapu Sravani
}

\begin{abstract}
Aim: This study was undertaken to study the effect of three most commonly used dentifrices for denture cleaning and to find out any positive association between number of strokes by toothbrush and surface roughness of acrylic resin.

Materials and methods: About 40 acrylic rectangular blocks with high finish were polished until surface roughness was calculated as $0 \mu \mathrm{m}$. The materials tested were distilled water as a control group, Patanjali Dant Kanti, Colgate Total Cream, and Cleansodent as dentifrices. Stroking was done with dentifrices, and surface roughness readings were recorded at 1,000, 9,000, and 18,000 strokes.
\end{abstract}

Results: Patanjali Dant Kanti was found to have maximum abrasive potential followed by Colgate Total Cream, followed by Cleansodent and least by distilled water.

Conclusion: Surface roughness was found to be directly proportional to the type, size, and fineness of the abrasive component used; the professional denture cleanser (Cleansodent) has less abrasive potential than the regular toothpastes. Among those tested, the highest abrasive potential was found in Patanjali Dant Kanti and lowest by Cleansodent (denture cleanser).

Clinical significance: The patient as well as dentist should choose the dentifrice with utmost care noting the size and type of abrasives used. Washing the dentures normally with water without toothbrush daily and cleaning of dentures once in 10 to 15 days with a soft toothbrush and professional denture cleanser should be the line of maintenance of dentures.

Keywords: Abrasive, Acrylic, Dentifrice, Denture.

\footnotetext{
1,2Department of Prosthodontics, Indira Gandhi Government Dental College \& Hospital, Jammu, Jammu and Kashmir, India

${ }^{3}$ Department of Prosthodontics, Government Dental College Srinagar, Jammu and Kashmir, India

${ }^{4-6}$ Department of Prosthodontics, MNR Dental College \& Hospital, Sangareddy, Telangana, India

Corresponding Author: Nitin Gautam, Department of Prosthodontics, Indira Gandhi Government Dental College \& Hospital, Jammu, Jammu and Kashmir, India, e-mail: nitingautam 212@gmail.com
}

How to cite this article: Gautam N, Sharma A, Bashir U, Rapolu S, Mamatha N, Sravani S. Effect of Different Dentifrices on the Surface Roughness of Acrylic Resins: An in vitro Study. J Contemp Dent Pract 2017;18(8):679-682.

Source of support: Nil

Conflict of interest: None

\section{INTRODUCTION}

The modern era of dentistry has brought numerous techno-smart materials, but the prosthetic rehabilitation of the completely edentulous patients still lies with either acrylic resins or a combination of metals and acrylic resins. The use of acrylic resins began in the 1950s and still is the material of choice because of the ease of manipulation and maintenance, economical, and less stress transmission to underlying tissues. ${ }^{1}$ The acrylic resins are polished mechanically with the sequence of certain finishing and polishing abrasives to produce a high mirror-like finish called "Beilby layer". This high finish prevents the accumulation of food debris and microorganisms on the denture surfaces. ${ }^{2}$ Poor denture hygiene is a common problem encountered by dentists in complete denture patients which may contribute to halitosis, denture stomatitis, and angular cheilitis. ${ }^{3-5}$ Denture stomatitis has been reported in 11 to $67 \%$ of complete denture wearers, ${ }^{6}$ associated with Candida albicans. ${ }^{7}$ In cases of denture stomatitis, C. albicans colonies are recovered more frequently from the tissue-fitting surface of the acrylic resin denture as opposed to corresponding palatal mucosa. ${ }^{8}$

The use of denture cleansing solutions or tablets is recommended for removal of plaque and microorganisms, but still the cleaning of dentures with a toothbrush and toothpaste under running water is the most common technique employed by denture wearers.

Although the technique employed is easy and economical, this causes abrasion of acrylic resin leading to loss of Beilby layer followed by abrasion of acrylic 
resin and affecting surface roughness, color, and biofilm accumulation capability of resins. ${ }^{4,5}$ Normally, dentifrices available in the local market have water, sodium lauryl sulfate as detergent, foaming agent, color, flavoring agent, saccharin as a sweetening agent, binders, and abrasives. ${ }^{7}$ Most commonly used abrasives in toothpaste are calcium carbonate, silica, or charcoal. Denture cleansers have sodium perborate and sodium bicarbonate which increase alkalinity of water and remove debris or citric acid, which increases acidity to remove stains from denture surfaces. ${ }^{8}$ Several studies ${ }^{9-12}$ have proven the association of C. albicans and denture surfaces, but, to our knowledge, no study has been conducted to study the abrasive capacity of commonly used commercial brands of dentifrices on the acrylic resins. This study is conducted on the effect of three commonly available dentifrices and distilled water on the abrasive capacity of acrylic resins, and their effect on the surface roughness of acrylic resins is calculated. Null hypothesis states that no difference exists in the effect of dentifrices on the roughness of acrylic resins.

\section{MATERIALS AND METHODS}

Two commonly used dentifrices as groups II and III, distilled water as a control group, and one professional denture cleanser as group IV were used in the study (Table 1).

A rectangular brass die of $10 \mathrm{~mm} \times 10 \mathrm{~mm} \times 40 \mathrm{~mm}$ dimensions was used to create a mold for the preparation

Table 1: Commercial products used

\begin{tabular}{lll}
\hline Trade name & Manufacturer & Batch no. \\
\hline $\begin{array}{l}\text { Colgate Total } \\
\text { Cream }\end{array}$ & Colgate Palmolive India Ltd., India & BO6 \\
$\begin{array}{l}\text { Patanjali Dant } \\
\text { Kanti }\end{array}$ & $\begin{array}{l}\text { Patanjali Ayurved Ltd., Haridwar, } \\
\text { India }\end{array}$ & ACF04 \\
Cleansodent & $\begin{array}{l}\text { ICPA Health Products Limited, } \\
\text { Distilled water }\end{array}$ & $\begin{array}{l}\text { Ankleshwar, India } \\
\text { Mega pure, Thermo fisher scientific } \\
\text { limited, India, Batch no. - NJ2343 }\end{array}$ \\
\hline
\end{tabular}

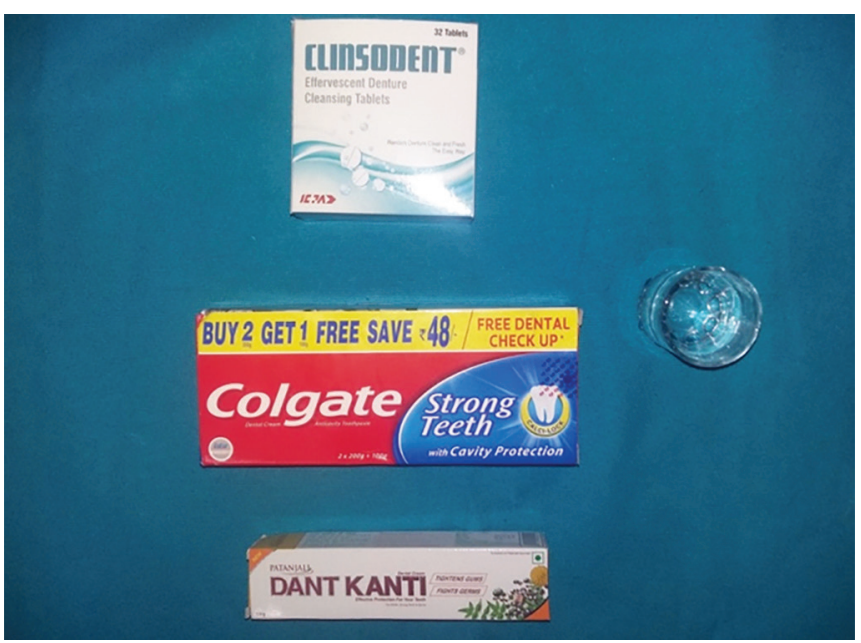

Fig. 2: Materials used of wax blocks, which were later invested in Hanau flasks for the preparation of the polymethyl methacrylate specimens using the conventional long-curing acrylization technique. About 40 rectangular acrylic blocks with same dimensions were prepared and sand-papered using a sequence of $80,120,220$, and 320 grit sandpaper to produce a high finish (Fig. 1). Each block was then polished using pumice and cotton buff.

About 40 polished acrylic blocks were kept in water for 20 days and were divided into four groups comprising 10 blocks in each group (Table 1 and Fig. 2). Each group was subjected to a specific dentifrice using an electric-powered toothbrush (Colgate, medium type of bristles) for 5 hours equivalent to 18,000 rotations. Surface roughness was calculated perpendicular to the center of the brushing cycles using roughness tester (Mitutoyo, Surface Roughness Tester, Takatsu-ku, Japan). Readings were made for each specimen at 0 strokes (base level), 1,000 strokes, 9,000 strokes (half way), and 18,000 strokes (complete cycle), and data were analyzed using analysis of variance and Student's t-test (Fig. 3).

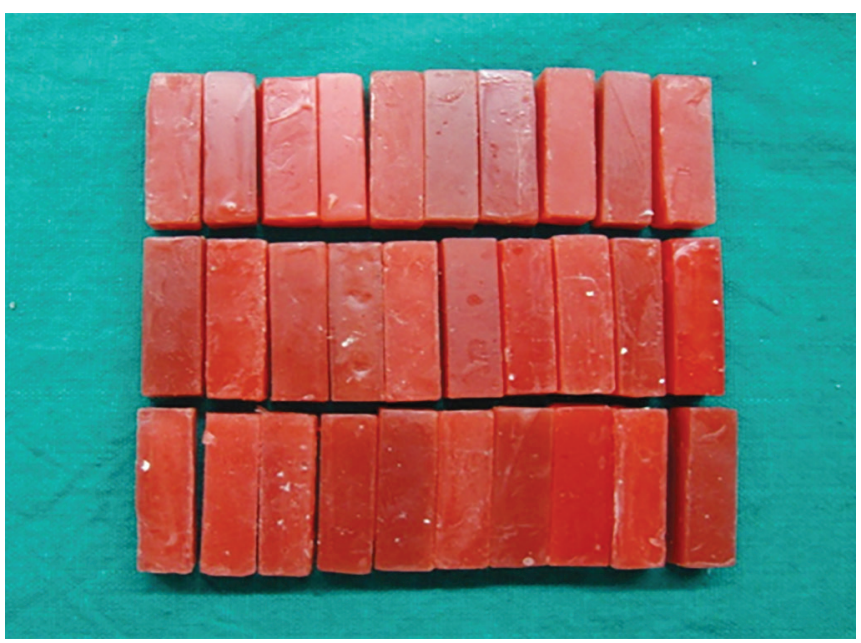

Fig. 1: Finished wax blocks

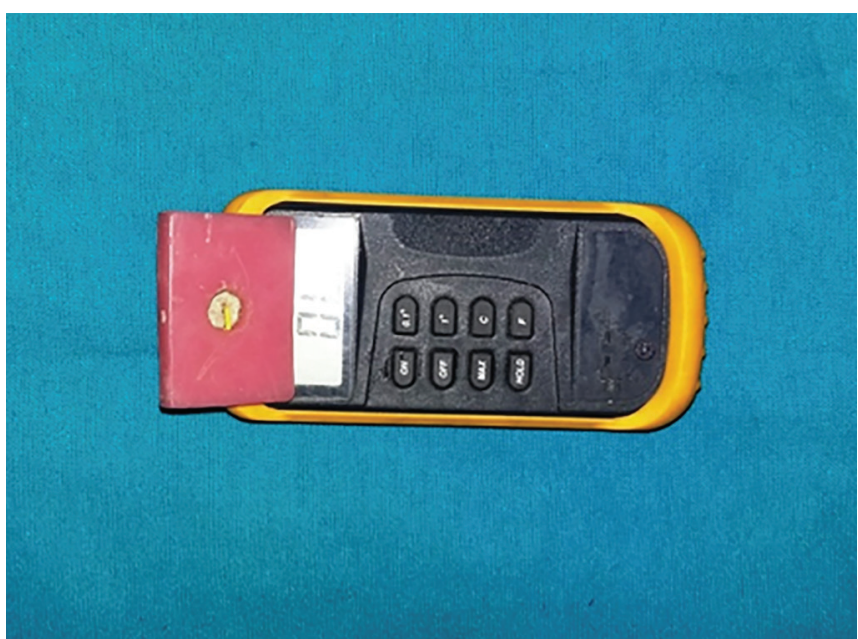

Fig. 3: Reading at 0 strokes of acrylic resins 
Effect of Different Dentifrices on the Surface Roughness of Acrylic Resins: An in vitro Study

Table 2: Surface roughness of various dentifrices after stroking with tooth brush

\begin{tabular}{|c|c|c|c|c|c|c|}
\hline Type of dentifrice & 0 strokes $(\mu \mathrm{m})$ & 1,000 strokes $(\mu \mathrm{m})$ & 9,000 strokes $(\mu \mathrm{m})$ & 18,000 strokes $(\mu \mathrm{m})$ & Mean values & Groups \\
\hline Distilled water & 0 & 0.12 & 10.2 & 24.7 & $8.75 \mu \mathrm{m}$ & $\mathrm{I}$ \\
\hline Colgate & 0 & 0.21 & 14.8 & 31.2 & $11.55 \mu \mathrm{m}$ & II \\
\hline Patanjali dant kanti & 0 & 0.26 & 17.0 & 36.4 & $13.41 \mu \mathrm{m}$ & III \\
\hline Cleansodent & 0 & 0.18 & 13.9 & 28.6 & $10.67 \mu \mathrm{m}$ & IV \\
\hline
\end{tabular}
$p<0.001$

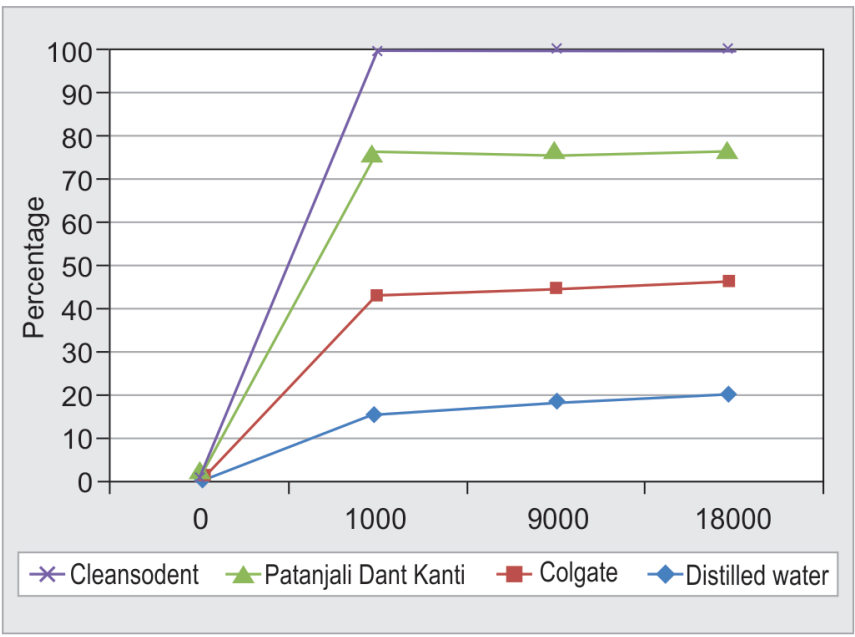

Graph 1: Abrasive values after stroking with different dentifrices

\section{RESULTS}

This study was conducted with the aim of evaluating the effect of dentifrices on the polished surface of acrylic resins. Mean values and standard deviations were calculated for all the four groups, and a direct association between the number of strokes and increase in surface roughness was found in the study $(p<0.001)$ (Table 2). Highest surface roughness was found after 18,000 strokes, followed by 9,000 strokes and least after 1,000 strokes. Furthermore, the type of dentifrice used had a significant role in the roughness of the resin tested. In intergroup comparison, the surface roughness was found to be highest for group III (13.41 $\pm 0.11 \mu \mathrm{m})$ followed by group II $(11.55 \pm 0.33 \mu \mathrm{m})$, group IV $(10.67 \pm 0.65 \mu \mathrm{m})$, and least by group I $(8.75 \pm 0.88 \mu \mathrm{m})(\mathrm{p}<0.001)$ (Graphs 1 and 2$)$.

\section{DISCUSSION}

Oral microbial flora has both aerobic and anaerobic species, which create equilibrium in the oral cavity. The presence of these bacteria creates an acidic environment below the prosthesis, favoring the growth of biofilm which if not removed causes candidiasis, fungal growth, and halitosis for the patient. ${ }^{11}$ With the aging of dentures, certain physical properties, such as color stability, roughness, porosity, and water sorption changes cause aging of the dentures. ${ }^{6}$ Cleaning of dentures is an important aspect which increases the longevity of prosthesis. Many people clean their dentures with water, some with toothbrush

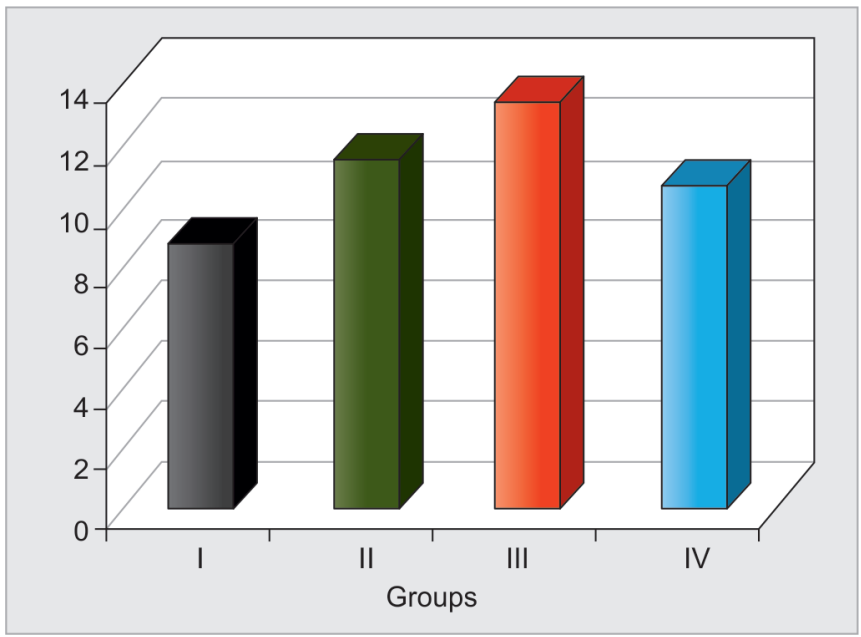

Graph 2: Mean value of stroking of all four groups

and toothpaste, and some with specific commercially available denture cleaning tablets. ${ }^{8}$

These denture cleansing tablets have chemicals which bond with the biofilm and eliminate it completely. We, in our study, have used distilled water, Cleansodent (peroxide) type denture cleanser dissolved in water, Colgate Total Active Cream, and Patanjali Dant Kanti, which contains abrasives of varying grades. When dissolved in water, it forms a solution of hydrogen peroxide. This type of cleanser combines alkaline detergents to reduce surface tension and chemicals that release oxygen from the solution. ${ }^{13}$ The oxygen bubbles exert a mechanical cleansing effect. Peroxide solutions are able to reduce C. albicans from denture bases. ${ }^{14}$

All the tested samples were cured in heat-cured denture resin and polished to a high finish with a surface roughness of $0 \mu \mathrm{m}$ to replicate denture surface and to establish a relationship between stroking and surface roughness. Null hypothesis that dentifrices have no effect on surface roughness stands rejected as a difference of $04.66 \mu \mathrm{m}$ exists between the groups when tested for surface roughness. Furthermore, highest surface roughness was found with maximum strokes and least with no strokes. Furthermore, it was found in the study that surface roughness was directly proportional to the number of strokes made by the toothbrush on the denture surface.

Standardization of the toothbrush was carried out using an electric-powered toothbrush to ensure no bias in the results. All the tested samples were measured initially 
before stroking, then after 1,000 strokes, midway, and finally, complete cycle to find out the association between number of strokes and surface roughness.

The results of this study suggest that maximum roughness was caused by the Patanjali Dant Kanti followed by Colgate Total Cream, Cleansodent denture cleansing tablets, and least by cleaning with distilled water. The reason can be attributed to the presence of abrasive component and the size of the abrasive particles. Richmond et $\mathrm{al}^{15}$ also confirmed the results that the abrasive potential of the dentifrices is due to the components, concentration, and size of the abrasive particles present in the dentifrice. Freitas and Paranhos ${ }^{16}$ also stated that cleaning of dentures without dentifrices causes less surface roughness than the toothbrush with dentifrice.

The results of this study are in accordance with the study by Ulusoy et $\mathrm{al}^{17}{ }^{17}$ which demonstrated lower surface roughness when abrasives of the finest grit are used in the dentifrices. The clinical implications of this study are of benefit to both dentists and patients. This study helps in establishing the role of dentifrices and their effect on the dentures. Furthermore, it gives a clear indication that only dentifrices with finest abrasives and of smallest sizes should be selected for usage. The dentures should be cleaned with distilled water daily without a toothbrush and with professional denture cleanser and toothbrush once in 10 days. Toothbrush of soft or ultrasoft bristles should only be used for cleaning purposes. The limitation of the study includes the absence of cyclic movements by the toothbrush, which can only be depicted in in vivo conditions. Further in vivo studies are directed toward usage of different dentifrices on the denture surfaces and the effect of different formulations of denture cleansers on the dentures. Furthermore, other properties like color stability, growth of microbials, and water sorption can be studied.

\section{CONCLUSION}

The professional denture cleanser (Cleansodent) has less abrasive potential than the regular toothpastes. Among tested, the highest abrasive potential was found in Patanjali Dant Kanti followed by Colgate Total Cream and lowest by Cleansodent (denture cleanser). The surface roughness was also found to be directly proportional to the type, size, and fineness of the abrasive component used.

\section{REFERENCES}

1. Heath JR, Davenport JC, Jones PA. The abrasion of acrylic resin by cleaning pastes. J Oral Rehabil 1983 Mar;10(2):159-175.
2. Verran J, Maryan CJ. Retention of Candida albicans on acrylic resin and silicone of different surface topography. J Prosthet Dent 1997 May;77(5):535-539.

3. Peracini A, Davi LR, de Queiroz Ribeiro N, de Souza RF, Lovato da Silva $\mathrm{CH}$, de Freitas Oliveira Paranhos H. Effect of denture cleansers on physical properties of heat-polymerized acrylic resin. J Prosthodont Res 2010 Apr;54(2):78-83.

4. Srinivasan M, Gulabani M. A microbiological evaluation of the use of denture cleansers in combination with an oral rise in complete denture patients. Indian J Dent Res 2010 Jul-Sep;21(3):353-356.

5. Lin JJ, Cameron SM, Runyan DA, Craft DW. Disinfection of denture base acrylic resin. J Prosthet Dent 1999 Feb;81(2): 202-206.

6. Khajuria RR, Madan R, Agarwal S, Gupta R, Vadavadgi SV, Sharma V. Comparison of temperature rise in pulp chamber during polymerization of materials used for direct fabrication of provisional restorations: an in-vitro study. Eur J Dent 2015 Apr-Jun;9(2):194-200.

7. Uludamar A, Özyesil AG, Ozkan YK. Clinical and microbiological efficacy of three different treatment methods in the management of denture stomatitis. Gerodontology 2011 Jun;28(2):104-110.

8. Williams DW, Kuriyama T, Silva S, Malic S, Lewis MA. Candida biofilms and oral candidiasis: treatment and prevention. Periodontol 20002011 Feb;55(1):250-265.

9. Kassab NH, Mustafa EA, Hasan RH. Antifungal effect: comparison of commercial denture cleansers and microwave energy diseases. Al Rafidain Dent J 2009;9(1):24-31.

10. Ma T, Johnson GH, Gordon GE. Effects of chemical disinfectants on the surface characteristics and color of denture resins. J Prosthet Dent 1997 Feb;77(2):197-204.

11. Hong G, Murata H, Li Y, Sadamori S, Hamada T. Influence of denture cleansers on the color stability of three types of denture base acrylic resin. J Prosthet Dent 2009 Mar;101(3): 205-213.

12. Canay S, Ergüven S, Yulug N. The function of enzymes in removing Candida accumulated on denture plaque. Med J Islamic World Acad Sci 1991;4(1):87-89.

13. JinC,NikawaH,MakihiraS, Hamada T, Furukawa M, Murata H. Changes in surface roughness and colour stability of soft denture lining materials caused by denture cleansers. J Oral Rehabil 2003 Feb;30(2):125-130.

14. Paranhos HF, Silva-Lovato CH, de Souza RF, Cruz PC, de Freitas-Pontes KM, Watanabe E, Ito IY. Effect of three methods for cleansing dentures on biofilms formed in vitro on acrylic resin. J Prosthodont 2009 Jul;18(5):427-431.

15. Richmond R, Macfarlane TV, McCord JF. An evaluation of the surface changes in PMMA biomaterial formulations as a result of toothbrush/dentifrice abrasion. Dent Mater 2004 Feb;20(2):124-132.

16. Freitas KM, Paranhos HF. Weight loss of five commercially available denture teeth after tooth brushing with three different dentifrices. J Appl Oral Sci 2006 Jul/Aug;14(4): 242-246.

17. Ulusoy M, Ulusoy N, Aydin AK. An evaluation of polishing techniques on surface roughness of acrylic resins. J Prosthet Dent 1986 Jul;56(1):107-112. 